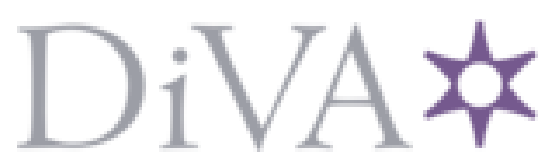

http://www.diva-portal.org

\title{
Postprint
}

This is the accepted version of a paper published in Journal of Clinical Nursing. This paper has been peer-reviewed but does not include the final publisher proof-corrections or journal pagination.

Citation for the original published paper (version of record):

Axelsson, L., Klang, B., Lundh Hagelin, C., Jacobson, S., Andreassen Gleissman, S. (2014)

Meanings of being a close relative of a family member treated with haemodialysis.

Journal of Clinical Nursing

http://dx.doi.org/10.1111/jocn.12622

Access to the published version may require subscription.

N.B. When citing this work, cite the original published paper.

Permanent link to this version:

http://urn.kb.se/resolve?urn=urn:nbn:se:shh:diva-1360 


\section{Meanings of being a close relative of a family member treated with haemodialysis approaching end of life}

Lena Axelsson, Birgitta Klang, Carina Lundh Hagelin, Stefan H Jacobson, Sissel Andreassen Gleissman

\section{Abstract}

Aims and objectives To describe and elucidate the meanings of being a close relative of a severely ill family member treated with maintenance haemodialysis coming to the end of life.

Background End stage renal disease together with co-morbidities, haemodialysis treatment, and high mortality rates also affect the lives of close relatives, who report burdens and impaired quality of life. To improve care more understanding is needed of close relatives' experiences during these patients' end of life.

Design This study has a qualitative interpretative design.

Methods Fourteen retrospective qualitative interviews were conducted with close relatives (aged 48 -93 years) of deceased patients who had been treated with haemodialysis. The interview text was interpreted using a phenomenological hermeneutical method in three phases.

Results. The findings of the structural analysis were formulated as six themes: Striving to be supportive and helpful without doing harm to the ill person's self; Needing increasing strength and support; Balancing the will to help with one's own ongoing life; Increasing responsibility involving dilemmas; Striving for a good life together in the present and Living with awareness of death. 
Conclusions. Close relatives strive for balance and well-being accompanying their ill family member through the end of life. They are facing moral dilemmas and growing demands as their responsibility increases with the deterioration of their family member. Support from and interaction with the health care professionals is then of significance

\section{Relevance to clinical practice.}

Findings challenge healthcare-professionals in haemodialysis settings to identify close relatives' individual resources and needs towards the patients' end of life. Healthcareprofessionals in haemodialysis settings need to offer close relatives opportunities to talk about the future, and what may be expected at end of life, with or without haemodialysis. They should also contact the closest relative after the death as they may need confirmation and closure.

Keywords. close relative, death, dying, end of life, end-stage renal disease, haemodialysis, phenomenological hermeneutics, qualitative interviews, retrospective interviews

What does this paper contribute to the wider global clinical community?

- Health care professionals should invite close relatives to talk about their thoughts for the future and what may be expected at the end of life and give them an opportunity to plan and prepare. Also written information, concerning illness consequences for the whole person and how to be supportive should be available.

- Close relatives expressed uncertainty about talking of death and dying. After death, some close relatives of patients treated with haemodialysis wished they had talked more to their ill family member about existential issues. Health care professionals in haemodialysis settings should support families in communicating about death.

- Lack of support may leave close relatives feeling alone and abandoned. After death they should be contacted by a health care professional at the dialysis clinic where their family member was earlier treated to facilitate closure. 


\section{INTRODUCTION}

The aging patient population with end stage renal disease (ESRD) suffer from the complexity of co-morbidities and symptoms (Weisbord et al. 2004; Santoro et al. 2013). Together with high mortality rates (SNR 2012, USRDS 2012) this has called for the need to integrate the holistic palliative care approach with nephrology care (Young 2009, Kurella Tamura \& Cohen 2010, Harrison \& Watson 2011). Thus the need for the principles of palliative care (WHO 2002) in the haemodialysis (HD) unit has been put forward (Madar et al. 2007, Noble et al. 2007, Axelsson et al. 2012a, Axelsson et al. 2012b). Palliative care philosophy addresses the needs of both patients and their families (WHO 2002). To develop care in the HD unit more understanding is needed of close relatives' experiences when patients approach end of life.

\section{Background}

Patients undergoing maintenance HD suffer an impaired quality of life (Kimmel \& Patel 2006, Davison \& Jhangri 2010) and a significant symptom burden (Davison et al. 2006, Saini et al. 2006, Murtagh et al. 2007).The interaction of co-morbidities such as diabetes, cardiac disease, cerebro-vascular disease, and peripheral vascular disease add to the complexity of their illness (Weisbord et al. 2003, Weisbord et al. 2005). ESRD and its life- sustaining treatment have also been recognized to affect the lives of both the patients and their close family members (White \& Grenyer 1999, Hagren et al. 2001). Family caregivers of patients undergoing dialysis experience a significant burden and an impaired quality of life (Lindqvist et al. 2000, Belasco \& Sesso 2002, Alvarez-Ude et al. 2004, Belasco et al. 2006) influenced by both emotions (Belasco \& Sesso 2002) and fatigue (Schneider 2004). Dealing with a family member's illness and treatment reduces a person's freedom and can come to dominate the life of the family member (Ziegert \& Fridlund 2001, Ziegert et al. 2009). Caring for the ill 
person at the expense of one's own health has been described (Ziegert et al. 2006). Patients' experiences of life with HD have also shown a strain on family life (Hagren et al. 2001, Polaschek 2003) and when the end of life approaches, dependence on families' crucial care increases as the patients become more vulnerable (Axelsson et al. 2012a). The desire not to be a burden is also included in patients' reasons to discontinue dialysis treatment (Ashby et al. 2005). A review (Low et al. 2008) of studies involving close persons of patients with ESRD identified few studies focusing on their experiences towards end-of-life. They found however that close persons experienced lack of preparation and information. A study (Noble et al. 2013) of experiences of close persons of dying patients where dialysis was not initiated found that they struggled to understand the illness situation with uncertain prognosis and death. In a review of end-of-life care in different contexts close relatives were found to have complex needs in a situation that could change from day to day (Andershed 2006). The complexity of patients declining health and the maintenance of life with advanced medical technology also affects close relatives. However, research into the lived experiences of close relatives towards end of life of patients in HD care is still scarce. To improve care the perspectives of close relatives should be further investigated.

\title{
METHODS
}

\begin{abstract}
Aim
The aim was to describe and elucidate the meanings of being a close relative of a severely ill family member treated with maintenance HD approaching end of life.
\end{abstract}




\section{Design}

This study has a qualitative interpretative design based on a phenomenological hermeneutical method (Lindseth \& Norberg 2004), inspired by Ricoeur (1976). The method combines the life-world philosophy of phenomenology and the hermeneutic tradition of text interpretation to illuminate the meanings of lived experience. The lived experience is individual but its meaning can be interpreted from interviews transcribed as autonomous text and thus understood and explained as a phenomenon of human experience (Ricoeur 1976, Lindseth \& Norberg 2004).

\section{Participants and setting}

Participants were recruited from three dialysis-clinics, two in university-hospitals and one satellite, situated in an urban area of Sweden. Inclusion criteria were I) being a close relative (mentioned in the medical record) of a deceased person who had been treated with HD and assessed as severely ill, and whose death therefore was not surprising, II) the ability to speak Swedish. With the assistance of a nurse all participants, but one, were identified through a search of the medical records of recently deceased patients at the dialysis clinics. The other participant was a close relative of a deceased participant of our earlier study (Axelsson et al. 2012a).

An information letter was sent to selected relatives. The letter outlined the aim of the study, the voluntary nature of participation, the right to withdraw participation at any time, our wish to audiotape the interview and to use quotations, and the confidential treatment of data. A few days later, the first author telephoned and offered additional information and asked potential participants for their consent to join the study. Six people declined to participate because of emotional stress or without giving a reason. 
Fourteen close relatives - two daughters, one son, one sister, nine wives, one husband participated. Participants' ages ranged from 48 to 93 years. Spouses had been married between 45 and 60 years.

The deceased persons had had besides ESRD a variety of co-morbidities including cardiac disease, previous stroke, peripheral vascular disease, diabetes, and cancer. Most had several co-morbidities. At four months before death 11 of the patients had lived at home, 2 had been in full-time institutional care, and 1 had been in institutional care as respite care. Only one died at home. Their age at death ranged from 71 to 87 years.

\section{Data collection}

Fourteen qualitative interviews (Kvale \& Brinkmann 2009) were conducted retrospectively (cf. Elkington et al. 2004, Williams et al. 2008). All interviews, except one, were performed in December 2011 to March 2012. Interviews were conducted 3 to 13 months after the death of the family member. Interviews took place according to the participants' wishes, 5 in participants' homes and 9 in either the participant's or the interviewer's private office. The participants were encouraged to narrate freely about their experiences and the interviews began with an open-ended question: "Please tell me about your spouse's (parent's or sister's) end of life". Audio-taped interviews (23 hours in total) were transcribed verbatim.

\section{Ethical considerations}

Participants were given written and verbal information outlining the voluntary nature of their participation, their right to withdraw, the wish to use quotations, and the respect of their confidentiality, before they gave their consent to participate. Interviews about the end-of-life should be conducted sensitively because of the distress they may invoke, but they may also be a positive experience for the interviewee (Scott et al. 2002, Dyregrov 2004, Koffman et al. 
2012). As interviews might invoke stress a contact at the dialysis clinic was available.

Participants were also invited to contact the interviewer after the interview. Ethical approval was granted by the Ethical Review Board.

\section{Data analysis}

In the first phase of interpretation, naive reading, the text was read as a whole several times with openness and closeness, and an initial understanding of its meaning was formulated. During structural analysis, the methodological second phase, all text was divided into meaning units (i.e. parts of the text containing a meaning relevant to the aim). Meaning units were condensed, abstracted, sorted, and organized into themes. The structural analysis was found to support the naive understanding. In comprehensive interpretation, the final phase, the naive understanding and the structural analysis were reflected on in the light of relevant literature and the authors' different pre-understandings. The interpretation process involved a dialectic movement between understanding the whole and explaining the parts and between closeness to and distance from the text (cf. Lindseth \& Norberg 2004, Ricoeur 1976).

\section{FINDINGS}

\section{Naive understanding}

Being a close relative when approaching end of life of a severely ill person treated with maintenance HD means living a life progressively burdened and heavy, but at the same time meaningful. It means striving for balance while being supportive through the ups and downs of severe illness. The ill person's weakness increases the relative's feelings of responsibility 
and their uncertainties and fears, also involving moral dilemmas. Increasing demands entails increasing needs of support and the close relative needs to be acknowledged in the vulnerable situation. Being a close relative means striving for well-being in the present and for a good end of life of their ill family member, and of their life together. Being aware that death is near may still involve feelings of being unprepared, but also of acceptance of having to let go.

\section{Structural analysis}

The findings of the structural analysis were formulated as six themes:

Striving to be supportive and helpful without doing harm to the ill person's self; Needing increasing strength and support; Balancing the will to help with one's own ongoing life; Increasing responsibility involving dilemmas; Striving for a good life together in the present and Living with awareness of death. Themes are illustrated in the text with representative quotations from interviews.

\section{Striving to be supportive and helpful without doing harm to the ill person's self}

Being a close relative means striving to be supportive and helpful without doing harm to the ill person's self. Participants expressed the demanded attentiveness related to the complexity of the ill person's ups and downs, but also to their slow and inevitable deterioration. Participants described being ready to step in to help, although they were perhaps not showing that readiness. Striving to be supportive involved hiding one's own feelings of sorrow or fatigue to protect the ill person from any feelings of shame or guilt.

I wept in between, I did, but mostly quietly on the side...I did not want to burden him with it, that I couldn't quite cope with it. 
Participants also strived to shield the ill person's deteriorating body from any risk of harm. However, close relatives expressed that protection also threatened the ill person's self and dignity.

Striving to be supportive also involved striving to encourage the ill person. This however involved participants' uncertainty about whether to talk of death and dying or not. This lead to neglecting the ill person's hints or questions related to death. This avoidance was also described as related to feeling incapable to confront one's fears. Some participants, however, wished they had talked more about existential issues; they regretted not knowing whether their family member had been afraid. A wife narrated what she would have liked to have done:

Been kinder ... more understanding ... made him more prone to open up and tell me things. How he felt, if he were scared... Had I done that I might have been able to help him more.

Supporting the ill person's self until death was significant for participants, who felt the dying family member ought to be recognized as a person by health care professionals. This was also important in the relatives' finding closure with dialysis personnel after the death of their loved one. A contact thus confirming them as important was significant. One spouse described her feelings when no one at the dialysis clinic contacted her after the death of her husband:

But absolutely dead quiet and that, in dark moments, I can feel disappointed about. Because, we were after all a part of their lives and they were part of our life for such a long, so long a time. 


\section{Needing increasing strength and support}

Narratives revealed that relatives wanted to help, but with growing demands they needed increasing strength and support. Among spouses strength were described as being together and struggling together. Some expressed involvement as sharing the illness. One spouse said:

Like, it was our disease, it wasn't only my husband's disease, it was our disease.

Some spouses described that a long close relationship gave them strength to meet challenges. Participants also expressed feeling strength in their satisfaction from helping their family member to maintain a good life. Caring gave meaning, and meaning brought strength. Participants expressed that they relied on their own inner strengths. Ways of gaining strength, such as being at work, going to the gym, or having some form of faith were described. Participants also expressed that sharing their own health with the ill person was a way to return support they had received earlier in life. Their feeling of having been able to comfort the dying person also helped them in their sorrow after death.

Well, even if it feels burdensome during the process, one feels, in spite of it all, kind of content with oneself, knowing that one has done one's best to ease things for one's partner.

Support as information and collaboration with healthcare-professionals became more important as the illness progressed, and the supporting relative's responsibilities and questions increased.

At such moments it is important that one ... gets some support ...

As he was that ill and they knew that he would pass away, because they obviously

knew that he wouldn't survive ... so.

Would you have liked to talk more about it?

Yes, that I would have liked to talk to them about and how and ... 
When do you think you would have wanted that?

Well, that would have,... that would have been at the end when he was hospitalized and earlier as well, because ... he attended the dialysis clinic for quite some time and they could have informed that this and that might be the outcome but I didn't know that ... More information about how, how it will work and ... will he be much worse and all that kind of stuff, at the end.

Participants also asked for written information, intended specifically for relatives, concerning illness consequences for the whole person, what to expect and how to be supportive.

Strength and support was described also in terms of feelings of security and trust in healthcare-personnel. The complexity of co-morbidities left family members uncertain who was ultimately responsible or could help them to cope with the whole situation. Those who experienced having one person, physician or nurse, who they could always contact considered this important to their managing the situation. Trust emerged as an central issue as when a woman described how a nurse, through mediating security and understanding her situation, changed her husband's last hours from despair and insufficiency to comfort and peace. Being acknowledged during their most vulnerable times strengthened the relatives and contributed to their feelings of a good ending. It was also vital that the care needs of the ill family member were acknowledged.

When demands and capacities were unbalanced the will to help could change into burden. A daughter said:

It felt like, the more chores I took upon myself, the more chores they (careprofessionals) added on. 
Yes, because they well knew that I carried them out. I fixed it.

Sometimes I was very sad and very tired

At times the burden was too heavy and they became angry and then hopeless and remorseful. Imbalance was endurable for a short time when the challenge of caring seemed meaningful, but recovery from the caring, concern, and challenge was a long-term process. Not all participants, however, expressed experiences of imbalance.

Lack of support from health care professionals left some relatives feeling abandoned although there was support from family or friends. Narratives illuminated that it may be difficult for relatives to show their need of support in their most vulnerable times.

There was never anyone asking how I was. Sometimes I could miss that, I thought they could well have asked how ... Because sometimes when I at night came home from the hospital I felt so lonely with everything ...

Like, sitting all by myself here thinking of many things and then I thought, they could have sat with me and talked to me when I was there.

\section{Balancing the will to help with one's own ongoing life}

Some described the ill person's illness as an influence on the whole family. The will to help was also to be balanced with the participants' own ongoing lives, and described as having to "tend to one's own life”. One daughter said:

Sure, she was part of my life but... it couldn't totally dominate either, you know. At times I was a bit testy saying I' $m$ going home now, I can't manage any more. But...my life was also going on.

As the illness progressed the dialysis treatment however changed for some participants from being a hindrance to being a moment of respite, while others found themselves tied to the sessions as they felt they should be there to ease the difficulties of the dialysis. Some 
participants described that the illness and schedules of dialysis took over their own lives. Some did not realize until after the death how tied down and burdened they had been.

Being old and having some illness themselves also increased relatives' vulnerability. The need for practical support at home was a complex issue for both patients and spouses involving questions of integrity and independence. Some managed on their own or with help from family or friends.

\section{Increasing responsibility involving dilemmas}

Responsibilities for the ill person could change incrementally with the deterioration of their health. Responsibilities could also increase quickly and change with fluctuating health, leading to worries such as when to call an ambulance or what might happen were the ill person left alone. Being responsible also induced feelings of becoming an agency to coordinate between different care-professionals.

Increasing responsibility also involved difficult moral dilemmas as questions about resuscitation or dialysis withdrawal. Participants felt responsible for preventing an undignified death and for making the right decision at the right moment. Most participants had not earlier discussed these options with the ill family member. They either had not thought of it or they thought it was too difficult. Some felt they knew the wishes of the ill person, either from previous hints or because they truly felt they knew the person. Participants said that decisions of care and life or death should be the own person's autonomous decisions, but with increasing illness some were involved. One spouse narrated her answer when the question of withdrawal was raised at the dialysis clinic: 
As long as you deem that you can ... then give him dialysis because...he wants to live, and he knows well that he won't if he stops dialysis, so ... Sometimes I had a feeling of, that they thought he was too ill

Even if the question of HD withdrawal was considered reasonable by close relatives, the way it was communicated or further handled could trouble them and make an already complex and sensitive situation worse. One daughter reflected:

One has to know as a patient, that I have this possibility to decide over my life. That I have the right to say that now I don't want this anymore. Because one might think, now I'm in this process, I have accepted dialysis, so, the question is not incorrect

She further narrated that she would have wanted to have been told beforehand that her mother was asked about withdrawal. Then she would have been prepared to deal with her mother's sorrow when she returned from the dialysis session. Participants expressed the importance of being invited to talk about their family member's situation and treatment.

This reoccurring thing that staff tell us, that mother should cease with ... dialysis treatment... That's what I have reacted to like that they have not invited us to a dialogue talking about how bad mother really is.

A daughter narrated that she felt the question of withdrawal from dialysis was as criticism of her mother's quality of life. Another participant described her dilemmas when she was asked to talk to her mother about dialysis withdrawal: 
... that I cannot decide for my mother, no. And is she in such a state that she, herself, can make such a decision? Did she understand the whole meaning, what that would imply?

Moral dilemmas also appeared when disagreeing with the ill person in difficult situations, as when the ill person refused to go to hospital. When a decision was taken against the will of the ill person the relative needed support from others that the decision was right, or a later consent from the ill person, as feelings of guilt arose.

\section{Striving for a good life together in the present}

Being a close relative, during the end of life of an ill family member, means striving for a good life together in the present. Participants expressed finding new ways to enjoy life. We tried to make these small moments into something other than dialysis and fatigue.

Achieving tolerance towards life and its restrictions was described as a help to their seeing what is good in a situation that can't be altered. To live as normally as possible appeared to support their balance in life and to keep to well-known routines involved feelings of security. Taking one day at the time was a way to cope with the challenges of the ill person's condition and to enjoy life towards the end. One participant said, "We lived in the present. Yes. Because we felt good there."

\section{Living with awareness of death}

Living with awareness of death means knowing that the old and severely ill family member may not live with HD very long. Some participants described having lived with an underlying awareness of the threat of death since the beginning of HD treatment. Some participants expressed wishes to have had occasions to ask their questions, others had earlier been informed about the prognosis which they appreciated: "It was in no way negative but 
concrete, this is it and this is what one can expect in a situation like this. "However, they were not sure if the ill person had perceived the information or situation correctly, or wanted to know, and they did not talk about it.

The complicated situation with co-morbidities contributed to the threat and declining health was a reminder of impending death. However, this awareness could hover at a distance as an inexplicit sorrow. Some participants described getting used to a fluctuating illness with critical situations, creating the feeling that the ill person would survive this time as last time. Others described being prepared for years that this fluctuating illness could yet end in a sudden farewell at any time. Even though death was unpredictable, the ill person's weakening body was a sign of reaching the end of the path towards death and of their life together. One spouse said:

That one of us has to go first, one didn't grasp that before.

No, but at the end I said to him that one of us must go first. "Then I hope it will be me”, he said ... and clearly I agreed with him, since I saw him get worse and worse.

Narratives revealed that awareness of death may still involve feelings of being unprepared, as it was difficult for participants to grasp the closeness of death, since awareness is not the same as understanding.

\section{DISCUSSION}

\section{Comprehensive interpretation and reflections}

The interpretation reveals a pattern of close relatives who strive for balance and well-being in their complex lives accompanying the ill family member on the path towards end of life, including balance for the ill person and balance for oneself. This means striving to be 
supportive, without harming the ill person, and this demands flexibility and thoughtfulness challenged by fluctuating illness and deterioration. Relatives expressed a will to help that both required and gave them strength. When balancing growing demands on the path towards their family members' end-of-life, their increasing need for support and interaction with healthcare-professionals became evident. Findings of striving for balance in life with the ill person may be illuminated by the philosopher Gadamer's (1996) description of health as inner equilibrium and in the continuum of the rhythm of life we strive always to regain balance. When close relatives accompany their ill family member towards end of life, their life rhythm is changed and challenged by the fluctuating illness and the ill person's increasing dependence in the continuum from living towards dying. The relatives' will to help, and their finding meaning and strength in helping, may be interpreted as an ontological expression of human caring, which contributes to their regaining balance and harmony in life. This is illuminated by the philosopher Logstrup's (1997) description of human beings as interdependent, with our lives lying in each other' hands. We thus have a responsibility for the lives of others as an ethical demand, even when this interferes with our own life - as expressed by the relatives in this study. Caring for the other, however, can never mean taking over the others own responsibility and it demands understanding the other's own understanding of life (Logstrup 1997). Our findings show that relatives strived to help and support their family member in an understanding and respectful way, and never to harm the ill person's self at the end-of-life. This may be interpreted as an expression of mutuality and the ethical demand (Logstrup 1997).

Narratives revealed that with increasing demands, increasing strength was needed. Relatives expressed that their caring was meaningful hence gave them strength. Strength was also gained by "sharing" the illness. Participants also expressed relying on their own inner strength when facing the challenges during end-of-life. Findings in themes are consistent with inner 
strength described by Lundman et al. (2010) as an interaction of connectedness, firmness, flexibility, and creativity. Further they describe inner strength as shouldering responsibility for others and enduring difficulties (Lundman et al. 2010). However, our findings show that with increasing demands, support from healthcare-professionals were of increasing significance. Collaboration and being acknowledged strengthened the relatives in their vulnerable situation while lack of support was expressed as feeling alone and abandoned. When demands and capacities were unbalanced the will to help could change into burden. This sometimes resulted in anger or sorrow followed by remorse and guilt. Carlander et al. (2011) found in a study close to death of persons' with cancer or severe heart problem that unbalanced responsibility involving feelings of guilt and insufficiency had a draining effect and affected relatives' self-image. Andershed and Ternestedt $(1998,1999,2000)$ described relatives involvement in care of patients with cancer at end-of-life as "involvement in the light" or "involvement in the dark." Being involved in the light meant being met with respect, openness, sincerity, confirmation, and connection in interaction with the staff, while the opposite was described as involvement in the dark (Andershed \& Ternestedt 2000). Our findings of the significance of communication, collaboration, trust and acknowledgement in interaction with healthcare-professionals agree with their understanding.

Glaser and Strauss (1965) described different contexts of awareness of death which may transform with changes in interaction. Long illness in chronic disease with co-morbidities makes awareness a complex issue to everyone concerned. This further challenges the communication between all involved to make time an opportunity for family preparation, rather than an impediment because of uncertainty (Glaser \& Strauss 1965). The need for and/or lack of preparation is identified also in earlier studies of close relatives of patients with ESRD (Low et al. 2008). Our findings high-light the importance of involvement and 
communication earlier in illness and HD treatment, as an early relation of openness may facilitate support also when death is unpredictable.

Earlier studies show hesitation to talk to each other about death (Collins \& Lehane 2013, Noble et al. 2013). In the present study the uncertainty about talking about death and dying with the ill person left some relatives wishing they had talked more of existential issues before death. Thoughts and feelings relating to death and dying have also shown (Axelsson et al. 2012b) to be significant and complex for patients living with HD. However, the desire to protect their family entailed facing existential loneliness. These findings may help healthcareprofessionals in their support to families in communicating about death.

Our findings show that when relatives were facing the question of HD withdrawal the way it was communicated or handled was vital in an already complex and sensitive situation. This shows that an understanding of the relatives' perspectives is crucial. Our findings also show the significance of contact with well-known HD personnel after death of the family member. After a long period of HD treatment and contact, relatives may need confirmation and closure for a good ending. A personal contact contributes to feelings that the deceased person was respected and important in the HD unit, which may be vital for the grieving relative.

\section{CONCLUSION}

Close relatives strive for balance and well-being accompanying their ill family member through the end-of-life. They are facing dilemmas and growing demands as their responsibilities increase with the deterioration of their family member. Findings show that support and interaction with the helth care professionals is of significance and that showing a will to understand relatives' perspective is of vital importance for how the situation is perceived. Findings indicate that open communication and acknowledgement may alleviate their suffering. 


\section{RELEVANCE TO CLINICAL PRACTICE}

Findings challenge healthcare-professionals in HD settings to identify close relatives' individual resources and needs towards the end of life. Healthcare-professionals need to offer opportunities to talk about the future, the prognosis, and what may be expected at end of life, with or without HD. It is important to create a supportive relationship of trust and offer opportunities to talk about death and dying and support families in communicating about death. Healthcare-professionals in the HD unit should contact the closest relative after the death as they may need confirmation and closure after the deceased's long period of dialysis treatment. Health care professionals should also work to improve the organization of care to facilitate the complex situations of the ill persons' co-morbidities and HD treatment towards the end of life. A palliative care approach in the HD unit, where support to family is a main focus, may assist.

\section{METHODOLOGICAL CONSIDERATIONS}

Retrospective interviews may be considered a limitation since narratives based on memory may be reconstructions, but this is a well-known method to research end-of-life (Williams et al. 2008). There is no consensus on the best timing for retrospective interviews. The variation of the interval (3-13 months) between the death of the family member and the interview may therefore add to credibility. Interviews yielded rich text of lived experiences and fourteen interviews were thus considered satisfactory to elucidate meanings of being a close relative during end-of-life. A majority of participants were spouses and women, which should be considered regarding transferability, however this also mirrors reality as ESRD is more 
prevalent among men. However, close relatives of various relations, ages and both sexes participated, which contributed to richness in the data and thus to increased credibility (Graneheim \& Lundman 2004, Patton 2002).

The interviewer strived to be open and compliant to encourage free narratives, which supports the credibility (Graneheim \& Lundman 2004, Lindseth \& Norberg 2004).

While interpreting the text the authors strived to be as open as possible and our different preunderstandings contributed to critical reflection and discussion. Ricoeur (1976) argues that there are several possible interpretations of any text. However, after argumentative discussions we agreed upon this interpretation. Representative quotations further contribute to trustworthiness (Graneheim \& Lundman 2004). We consider findings to be transferable to similar contexts; readers ' judgements of transferability are facilitated by the description of participants and the context.

\section{Author contributions}

Study design: LA, BK, CLH, SHJ, SAG; data collection: LA; data analysis; LA, BK, CLH, SAG; manuscript preparation; LA, BK, CLH, SHJ, SAG

\section{Acknowledgements}

This research was supported by grants from Sophiahemmet Foundation, Stockholm, Sweden and The Swedish Society of Nursing (SSF).

\section{Conflict of interest}

None. 


\section{REFERENCES}

Alvarez-Ude F, Valdes C, Estebanez C \& Rebollo P (2004) Health-related quality of life of family caregivers of dialysis patients. Journal of Nephrology 17, 841-850.

Andershed B (2006) Relatives in end-of-life care--part 1: a systematic review of the literature the five last years, January 1999-February 2004. Journal of Clinical Nursing 15, 1158-1169.

Andershed B \& Ternestedt BM (1998) Involvement of relatives in the care of the dying in different care cultures: involvement in the dark or in the light? Cancer Nursing 21, 106-116.

Andershed B \& Ternestedt BM (1999) Involvement of relatives in care of the dying in different care cultures: development of a theoretical understanding. Nursing Science Quarterly 12, 45-51.

Andershed B \& Ternestedt BM (2000) Being a close relative of a dying person. Development of the concepts "involvement in the light and in the dark". Cancer Nursing 23, 151-159.

Ashby M, op't Hoog C, Kellehear A, Kerr PG, Brooks D, Nicholls K, Forrest M (2005) Renal dialysis abatement: lessons from a social study. Palliative Medicine 19, 389-96.

Axelsson L, Randers I, Jacobson SH \& Klang B (2012a) Living with haemodialysis when nearing end of life. Scandinavian Journal of Caring Sciences 26, 45-52.

Axelsson L, Randers I, Lundh Hagelin C, Jacobson SH \& Klang B (2012b)Thoughts on death and dying when living with haemodialysis approaching end of life. Journal of Clinical Nursing 21, 2149-2159.

Belasco A, Barbosa D, Bettencourt AR, Diccini S \& Sesso R (2006) Quality of life of family caregivers of elderly patients on hemodialysis and peritoneal dialysis. American Journal of Kidney Diseases 48, 955-963. 
Belasco AG \& Sesso R (2002) Burden and quality of life of caregivers for hemodialysis patients.

American Journal of Kidney Diseases 39, 805-812.

Carlander I, Ternestedt BM, Sahlberg-Blom E, Hellstrom I \& Sandberg J (2011) Being me and being us in a family living close to death at home. Qualitative Health Research 21, 683-695.

Collins M \& Lehane E (2013) Perspectives on death, dying and advance care planning from patients receiving haemodialysis. Journal of Renal Care, 39, 5-11.

Davison SN \& Jhangri GS (2010) Impact of pain and symptom burden on the health-related quality of life of hemodialysis patients. Journal of Pain and Symptom Management 39, 477-485.

Davison SN, Jhangri GS \& Johnson JA (2006) Cross-sectional validity of a modified Edmonton symptom assessment system in dialysis patients: a simple assessment of symptom burden. Kidney International 69, 1621-1625.

Dyregrov K (2004) Bereaved parents' experience of research participation. Social Science \& Medicine 58, 391-400.

Elkington H, White P, Addington-Hall J, Higgs R \& Pettinari C (2004) The last year of life of COPD: a qualitative study of symptoms and services. Respiratory Medicine 98, 439-445.

Gadamer H-G (1996 )The enigma of health. The Art of Healing in a Scientific Age. Polity Press, Cambridge

Glaser BG \& Strauss, AL (1965/2005) Awareness of dying, Aldine, Chicago, IL.

Graneheim UH \& Lundman B (2004) Qualitative content analysis in nursing research: concepts, procedures and measures to achieve trustworthiness. Nurse Education Today 24, 105-112

Hagren B, Pettersen IM, Severinsson E, Lutzen K \& Clyne N (2001) The haemodialysis machine as a lifeline: experiences of suffering from end-stage renal disease. Journal of Advanced Nursing 34, 196-202.

Harrison K \& Watson S (2011) Palliative care in advanced kidney disease: a nurse-led joint renal and specialist palliative care clinic. International Journal of Palliative Nursing 17, 42-46.

Kimmel PL \& Patel SS (2006) Quality of life in patients with chronic kidney disease: focus on endstage renal disease treated with hemodialysis. Seminars in Nephrology 26, 68-79. 
Koffman J, Higginson IJ, Hall S, Riley J, McCrone P \& Gomes B (2012)Bereaved relatives' views about participating in cancer research. Palliative Medicine 26, 379-383.

Kurella Tamura M \& Cohen LM (2010) Should there be an expanded role for palliative care in endstage renal disease? Current Opinion in Nephrology and Hypertension 19, 556-560.

Kvale SB \& Brinkmann S (2009) Interviews: Learning the craft of qualitative research interviewing. Sage Publications, Thousand Oaks CA.

Lindqvist R, Carlsson M \& Sjoden PO (2000) Coping strategies and health-related quality of life among spouses of continuous ambulatory peritoneal dialysis, haemodialysis, and transplant patients. Journal of Advanced Nursing 31, 1398-1408.

Lindseth A \& Norberg A (2004) A phenomenological hermeneutical method for researching lived experience. Scandinavian Journal of Caring Sciences 18, 145-153.

Logstrup KE (1997) The Ethical Demand. University of Notre Dame Press, Notre Dame.

Low J, Smith G, Burns A \& Jones L (2008) The impact of end-stage kidney disease (ESKD) on close persons: a literature review, NDT Plus 2, 67-79.

Lundman B, Alex L, Jonsen E, Norberg A, Nygren B, Santamaki Fischer R \& Strandberg G (2010) Inner strength--a theoretical analysis of salutogenic concepts. International Journal of Nursing Studies 47, 251-260.

Madar H, Gilad G, Elenhoren E \& Schwarz L (2007) Dialysis nurses for palliative care. Journal of Renal Care 33, 35-38.

Murtagh FE, Addington-Hall J \& Higginson IJ (2007)The prevalence of symptoms in end-stage renal disease: a systematic review. Advances in Chronic Kidney Disease 14, 82-99.

Noble H, Kelly, D., Rawlings-Anderson, K. \& Meyer, J (2007) A concept analysis of renal supportive care: the changing world of nephrology. Journal of Advanced Nursing 59, 644-653.

Noble H, Kelly D \& Hudson P (2013) Experiences of carers supporting dying renal patients managed without dialysis. Journal of Advanced Nursing, 69, 1829-39. doi: 10.1111/jan.12049. Epub 2012 Nov 20

Patton M Q (2002) Qualitative research \& evaluation methods. Sage, London: 
Polaschek N (2003) The experience of living on dialysis: a literature review. Nephroly Nursing Journal 30, 303-309, 313.

Ricoeur P (1976) Interpretation theory: discourse and the surplus of meaning. Texas Christian University Press, Forth Worth, Texas.

Saini T, Murtagh FE, Dupont PJ, McKinnon PM, Hatfield P \& Saunders Y (2006) Comparative pilot study of symptoms and quality of life in cancer patients and patients with end stage renal disease. Palliative Medicine 20, 631-636.

Santoro D, Satta E, Messina S, Costantino G, Savica V \& Bellinghieri G (2013) Pain in end-stage renal disease: a frequent and neglected clinical problem. Clinical Nephrology 79, 2-11.

Schneider RA (2004) Chronic renal failure: assessing the Fatigue Severity Scale for use among caregivers. Journal of Clinical Nursing 13, 219-225.

Scott DA, Valery PC, Boyle FM \& Bain CJ (2002) Does research into sensitive areas do harm? Experiences of research participation after a child's diagnosis with Ewing's sarcoma. Medical Journal of Australia 177, 507-510.

SNR, Svenskt njurregister (Swedish Renal Registry) Annual data report. 2012 [cited 20130302]; Available from: http://www.medscinet.net/snr/rapporterdocs/Årsrapport\%202012.pdf USRDS. U S Renal Data System 2012, Annual Data Report: Atlas of Chronic Kidney Disease and End-Stage Renal Disease in the United States 2012 [cited 20130302]; Available from: http://www.usrds.org/atlas.aspx

Weisbord SD, Carmody SS, Bruns FJ, Rotondi AJ, Cohen LM, Zeidel ML \& Arnold RM (2003) Symptom burden, quality of life, advance care planning and the potential value of palliative care in severely ill haemodialysis patients. Nephrology Dialysis Transplantation 18, 13451352.

Weisbord SD, Fried LF, Arnold RM, Rotondi AJ, Fine MJ, Levenson DJ, Switzer GE (2004) Development of a symptom assessment instrument for chronic hemodialysis patients: the Dialysis Symptom Index. Journal of Pain Symptom Management 27, 226-240. 
Weisbord SD, Fried LF, Arnold RM, Fine MJ, Levenson DJ, Peterson RA \& Switzer GE (2005) Prevalence, severity, and importance of physical and emotional symptoms in chronic hemodialysis patients. Journal of the American Socety of Nephrology 16, 2487-2494.

White Y \& Grenyer BF (1999) The biopsychosocial impact of end-stage renal disease: the experience of dialysis patients and their partners. Journal of Advanced Nursing 30, 1312-1320.

Williams BR, Woodby LL, Bailey FA \& Burgio KL (2008): Identifying and responding to ethical and methodological issues in after-death interviews with next-of-kin. Death Studies 32, 197-236.

World Health Organization (2002) WHO Definition of Palliative Care Available from: http://www.who.int/cancer/palliative/definition/en/ (accessed 12 May 2013).

Young S (2009) Rethinking and integrating nephrology palliative care: a nephrology nursing perspective. CANNT Journal 19, 36-44.

Ziegert K \& Fridlund B (2001) Conceptions of life situation among next-of-kin of haemodialysis patients. Journal of Nursing Management 9, 231-239.

Ziegert K, Fridlund B \& Lidell E (2006) Health in everyday life among spouses of haemodialysis patients: a content analysis. Scandinavian Journal of Caring Sciences 20, 223-8.

Ziegert K, Fridlund B \& Lidell E (2009) "Time for dialysis as time to live": experiences of time in everyday life of the Swedish next of kin of hemodialysis patients. Nursing and Health Sciences 11, 45-50. 